\title{
Growth and characterization of $\mathrm{Na}_{3} \mathrm{BaCl}_{5} \cdot 2 \mathrm{H}_{2} \mathrm{O}$
}

\author{
S ASATH BAHADUR, V RAMAKRISHNAN* and R K RAJARAM \\ School of Physics, Madurai Kamaraj University, Madurai 625021 , India \\ MS received 10 March 1989; revised 8 July 1989

\begin{abstract}
Na}_{3} \mathrm{BaCl}_{5} \cdot 2 \mathrm{H}_{2} \mathrm{O}$ crystals were prepared by the slow evaporation of an aqueous solution of a mixture of sodium chloride and barium chloride in stoichiometric ratio. Crystals were found to possess platelet habit. Crystals were analysed by infrared spectrophotometry, thermogravimetry and X-ray diffraction. The appearance of bands due to stretching and bending modes of water molecules in the IR spectra showed that the grown crystals were hydrated. X-ray oscillation and Weissenberg photographs were used to measure the dimensions of the unit cell.
\end{abstract}

Keywords. $\mathrm{Na}_{3} \mathrm{BaCl}_{5} \cdot 2 \mathrm{H}_{2} \mathrm{O}$ crystals; IR spectra; thermogravimetric analysis; $\mathrm{X}$-ray diffraction studies; platelet habit.

\section{Introduction}

Compounds in the general formula $\mathrm{A}_{m} \mathrm{MX}_{n}$, where $\mathrm{A}$ is a univalent cation, $\mathrm{M}$ is a di- or trivalent metal and $\mathrm{X}$ is a halogen, exhibit unusual physical properties (Brosset 1937; Powell et al 1942). Such systems have attracted a great deal of attention owing to the occurrence of varying stoichiometries in these compounds. These crystals are known to exhibit paraelectric-ferroelectric phase transitions. Some systems even undergo five or six successive phase transitions (Ruiz Larrea et al 1981; Rathore et al 1987). Vibrational spectra of certain crystals belonging to this family have been obtained to understand the nature and dynamic behaviour of the various groups in these systems (Hasabe et al 1980; Sugiyama et al 1980). The growth and characterization of $\mathrm{Na}_{3} \mathrm{BaCl}_{5} \cdot 2 \mathrm{H}_{2} \mathrm{O}$, belonging to the metal halogen complexes, is reported here.

\section{Experimental}

Growth experiments were carried out by the slow evaporation method. Aqueous solutions of analytical reagent grade sodium chloride and barium chloride mixed in $3: 1$ ratio were allowed to evaporate slowly in a crystal-growing dish. $\mathrm{Na}_{3} \mathrm{BaCl}_{5}$. $2 \mathrm{H}_{2} \mathrm{O}$ was expected to crystallize out. Within 10 days platelet habits, transparent and prismatic crystals were formed at the bottom. The crystal obtained had maximum dimensions of $2 \times 8 \times 2 \mathrm{~mm}$ (figure 1). Nucleation was limited and growth of the crystals were completed within 15 days. All the experiments were carried out at a mean temperature of $30^{\circ} \mathrm{C}$.

\section{Results and discussion}

The grown crystals were analysed using X-ray, IR and thermogravimetric

*For correspondence. 


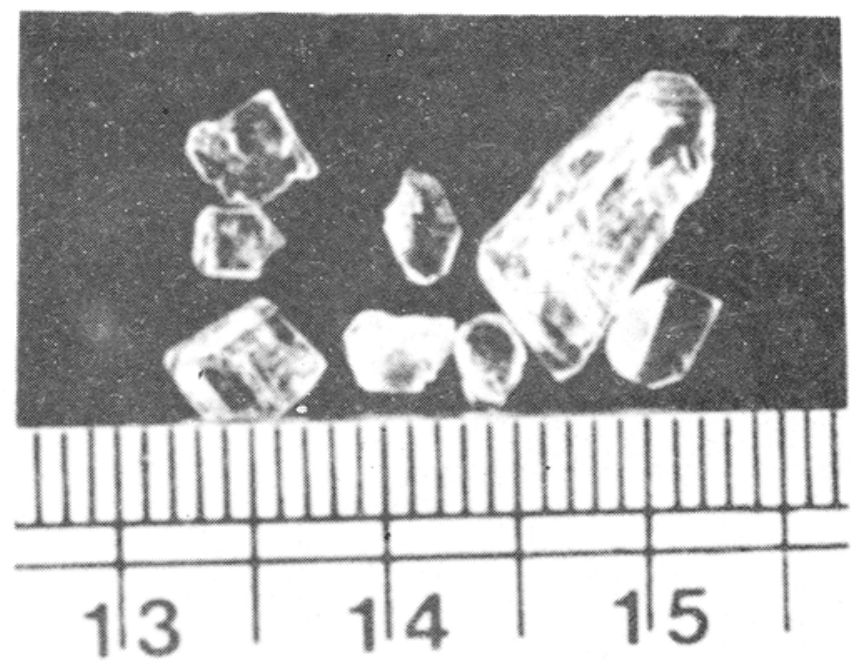

Figure 1. $\mathrm{Na}_{3} \mathrm{BaCl}_{5} \cdot 2 \mathrm{H}_{2} \mathrm{O}$ crystals obtained by the slow evaporation method.

Table 1. Preliminary crystallographic data.

\begin{tabular}{ll}
\hline Cell dimensions & $=7.206 \AA$ \\
$b$ & $=10.817 \AA$ \\
& $c=6.564 \AA$ \\
$\beta$ & $=92^{\circ}$ \\
& $=511.334 \AA^{3}$ \\
Volume of unit cell & $=2.722 \mathrm{~g} / \mathrm{cc}$ \\
Observed density & $=2.721 \mathrm{~g} / \mathrm{cc}$ \\
Calculated density & $=2$ \\
No. of molecules in the unit cell & $=419.6048 \mathrm{~g}$ \\
Formula weight & $=$ monoclinic \\
System & $=0 k 0-k$ odd absent \\
Systematic absences & \\
& \\
Space group & \\
\end{tabular}

techniques. The density of the above samples was determined by the floatation technique using bromoform and carbon tetrachloride mixture, and found to be $2.722 \mathrm{~g} / \mathrm{cc}$. The cell dimensions of the crystals were measured by the oscillation, zero layer and first layer Weissenberg technique (Buerger 1958) with nickel-filtered, $\mathrm{CuK}_{\alpha}$ radiation. The preliminary crystallographic data are presented in table 1.

IR spectrum (figure 2) of the grown crystals was recorded using a Perkin Elmer 588 spectrometer. The measurements were made using Nujol mull technique to avoid moisture absorption during sample preparation. The spectrum was expected to have bands due to the vibrations of $\mathrm{BaCl}_{4}$ and water groups. The vibrations of the $\mathrm{BaCl}_{4}$ group consist of internal and lattice vibrations. The stretching and bending frequencies of the $\mathrm{BaCl}_{4}$ group possessing $T_{d}$ symmetry are normally observed in the $250-300 \mathrm{~cm}^{-1}$ and $80-200 \mathrm{~cm}^{-1}$ regions respectively (Nakamoto 1978). The weak band at $260 \mathrm{~cm}^{-1}$ is due to the symmetric-stretching vibrations of the $\mathrm{BaCl}_{4}$ group. The appearance of a band due to this IR inactive 


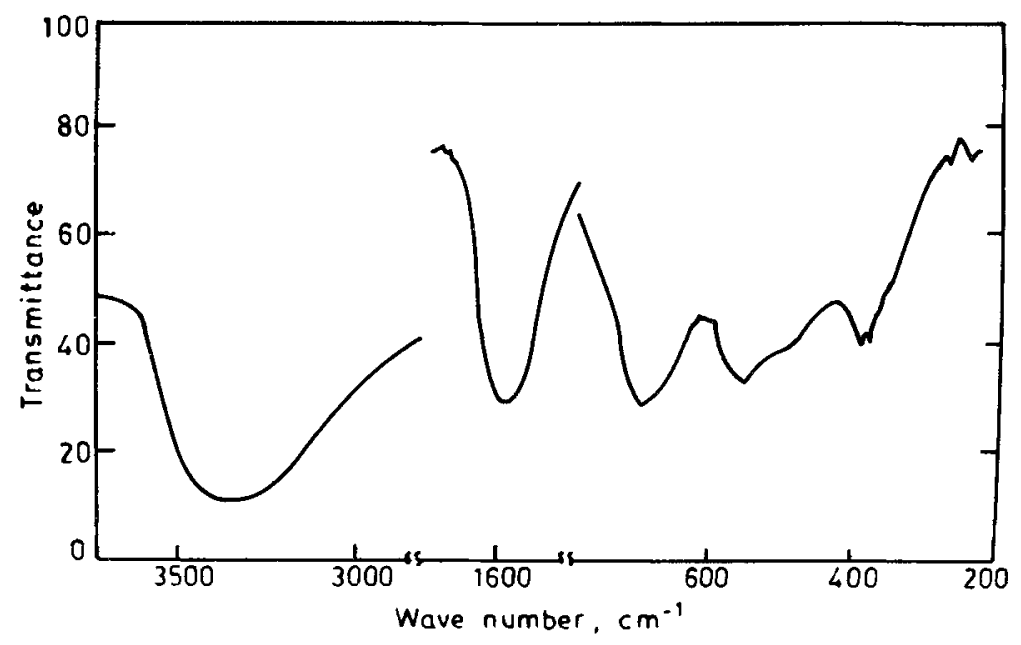

Figure 2. IR spectrum of $\mathrm{Na}_{3} \mathrm{BaCl}_{5} \cdot 2 \mathrm{H}_{2} \mathrm{O}$.

mode shows that the $\mathrm{BaCl}_{4}$ tetrahedron is distorted (Viswanathan et al 1988). The weak band which appears at $300 \mathrm{~cm}^{-1}$ is due to the asymmetric stretching mode.

The bands due to the bending vibrations of this group have not been observed as the lower limit of the instrument is up to $200 \mathrm{~cm}^{-1}$. The free water molecule has three normal modes with frequencies at 3650,1595 and $3750 \mathrm{~cm}^{-1}$ (Nakamoto 1978). The broad band covering the $3200-3500 \mathrm{~cm}^{-1}$ region indicates that the stretching frequencies of the water molecule overlap. The intense band at $1600 \mathrm{~cm}^{-1}$ is due to the bending vibrations of the water molecules. The water molecule has three librational modes (wagging, twisting and rocking). These modes are more sensitive to interactions involving hydrogen bonds and are less sensitive to those involving metal-oxygen coordinations. The low polarizability of water molecules makes these bands appear weak. Studies on these modes show that the assignments of these modes are ambiguous (Lutz et al 1979; Singh et al 1980). However, the frequencies observed in the $400-900 \mathrm{~cm}^{-1}$ region are tentatively assigned. The medium intensity bands at 700,570 and $400 \mathrm{~cm}^{-1}$ were due to the librational motions of the water molecules. IR spectrum reveals that in the slow evaporation process the product is obtained as a well-defined crystal containing water of crystallization.

For thermogravimetric analysis of the sample, runs were carried out in a nitrogen atmosphere in a Dupont 990 molecular thermal analysis system with 451 TGA. The heating rate was maintained at $10^{\circ} \mathrm{C} \mathrm{min}{ }^{-1}$, when the rate of flow of nitrogen was $50 \mathrm{~cm} \mathrm{~min}{ }^{-1}$. From the measurements on the weight loss against temperature (figure 3), it is quite clear that the crystals are hydrated. The computed value of the percentage of water suggests that the crystal has two water molecules.

\section{Conclusions}

(i) The crystals grown were characterized as $\mathrm{Na}_{3} \mathrm{BaCl}_{5} \cdot 2 \mathrm{H}_{2} \mathrm{O}$; (ii) The hydrated nature of the crystal is confirmed by density, IR and thermogravimetric 


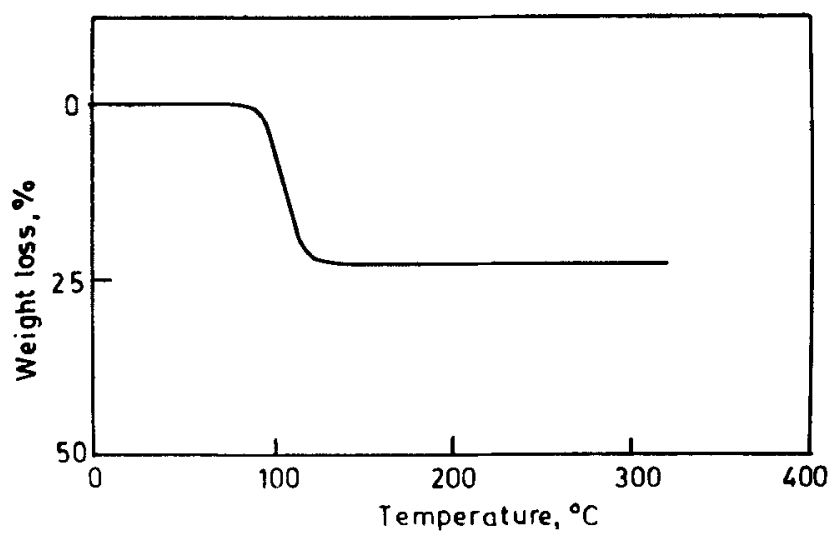

Figure 3. The dehydration of $\mathrm{Na}_{3} \mathrm{BaCl}_{5} \cdot 2 \mathrm{H}_{2} \mathrm{O}-\mathrm{TGA}$ data.

measurements. (iii) The crystals belong to the monoclinic system and the $P 2_{1} / n$ space group with two formula units per unit cell.

\section{Acknowledgements}

One of the authors (SAB) is grateful to the Madurai Kamaraj University for the award of a fellowship.

\section{References}

Brosset Z 1937 Z. Anorg. Allgem. Chem. 235139

Buerger M J $1958 X$-ray crystallography 4th edn (London: John Wiley and Sons)

Hasabe K, Mashiyama H and Tanisaki S 1980 J. Phys. Soc. Jpn. 491633

Lutz H D, Pobischke W, Christan H and Becker R H 1979 J. Raman Spectrosc. 7130

Nakamoto K 1978 Infrared and Raman spectra of inorganic and coordination compounds 3rd edn (New York: John Wiley and Sons) p. 136

Powell C and Wells $1942 \mathrm{~J}$. Chem. Soc. 642

Rathore R P, Khatri S S and Chakraborty T 1987 J. Raman Spectrosc. 18429

Ruiz Larrea I, Lopez-Echarri A and Tello M J 1981 J. Phys. C14 3171

Singh B, Gupta S P and Khanna B N 1980 Pramana-J. Phys. 14509

Sugiyama J, Wada M, Sawada A and Ishibashi Y 1980 J. Phys. Soc. Jpn. 491405

Viswanathan K, Nayar V U, Aruldhas G and Ramakrishnan V 1988 J. Solid State Chem. 77394 